\title{
Bioarchaeological Analysis of Human Skeletal Remains of Iron Age from the Shirakavan Cemetery, Shirak Plateau, Armenia
}

\author{
Anahit $\mathrm{Yu}$. Khudaverdyan \\ Institute of Archaeology and Ethnography National Academy of Science, Yerevan, Republic of Armenia Yerevan \\ Email: ankhudaverdyan@gmail.com, akhudaverdyan@mail.ru \\ Received September $7^{\text {th }}, 2012$; revised October $4^{\text {th }}, 2012$; accepted October $15^{\text {th }}, 2012$
}

\begin{abstract}
This study introduces some diseases which occur among the population of Armenia in the Iron Age. Health issues in the individuals from Shirakavan provoked not by nutritional problems, but problems of infectious nature. The skeletal traumas of the inhabitants of the Shirak plateau are connected only with military conflicts. The results of this study are those that suggest strenuous labor for at least some individuals, based on the presence of osteophytosis, osteoarthritis, enthesopathies, and Schmorl's nodes. Grooves on the occlusal surfaces of teeth are observed in individuals and were most likely produced during the processing of fibers from plants and animals, for making items such as cordage and baskets.
\end{abstract}

Keywords: Armenia; Iron Ages; Stress Markers; Trauma; Trepanation; Scalp; Degenerative Disease

\section{Introduction}

Bioarchaeology, or the study of archaeological human remains (Larsen, 1997), will make substantial contributions to our understanding of human adaptation and the biological history of the ancient population Armenian Highland. Because skeletal and dental tissues are sensitive to environmental fluctuations, they reflect a wide variety of human behaviors and conditions including diet, nutritional quality, treatment, nonspecific physiological stress, specific activity patterns, mobility levels, environmental and occupational hazards, exposure to pathogens and other disease processes and interpersonal violence (Larsen, 1997). By considering whole populations, rather than individual cases within them, bioarchaeologists can reconstruct overall patterns and compare populations with one another in order to gain better insights into behavior, lifestyle, subsistence patterns, and other aspects of human adaptation. The usefulness of skeletal lesions in evaluating health of prehistoric populations has been extensively demonstrated in the literature (e.g. Ortner \& Putschar, 1985; Roberts \& Manchester, 1995; Aufderheide \& Rodriguez-Martin, 1998; Steckel \& Rose, 2002), and the limitations of such studies have also been discussed (Buikstra \& Cook, 1980; Wood et al., 1992; Steckel et al., 2002). It is this population approach to bioarchaeology that is employed in the current study. Such studies have been done on various Armenian archaeological populations such as at Lchashen (II millennium BC-I millennium BC), Beniamin, Vardbakh, the Black Fortress (1st century BC-3rd century AD) and others (Khudaverdyan, 2010a, 2010b, 2010c).

\section{Estimation of the General State of Health Based on Stress Markers}

Cribra orbitalia and porotic hyperostosis. The behavior of these indicators in the skeletal sample allows us to evaluate nutrition and health condition in these individuals, as it permits us to approach the disorders related to nutritional deficiencies, such as that of iron that leads to anemia (El-Najjar et al., 1976;
Lallo et al., 1977; Stuart-Macadam, 1992; Aufderheide \& Rodriguez-Martin, 1998, Larsen, 1997). It is manifested as a widening of the spongy diploe with a corresponding thinning of the outer cortical bone table resulting in the appearance of surface porosity. In severe cases there is a total obliteration of the bone surface with a lattice of trabecular overgrowth (Goodman et al., 1984; Ortner \& Putshar, 1985). These lesions either first appear or show a frequency increase with sedentary farming suggesting that anemia is primarly a disease of these agricultural groups (Goodman et al., 1984).

Hypoplasia of dental enamel; from the pathological perspective, this indicator is due to a period of non-specific metabolic stress, caused by the lack of nutriments in a deficient alimentation or by infectious diseases, as well as parasitic ones that affect the normal absorption of nutriments, giving as a result insufficiency in the thickness of the enamel due to the interrupttion of amelogenesis or the formation of the enamel layer which covers the teeth (Larsen, 1997: p. 45).

The term osteomyelitis describes an infection of the bone and the bone marrow (Aufderheide \& Rodriguez-Martin, 1998). The disease is either caused by the pus-producing microorganism Staphylococcus aureus or by the bacterium Streptococcus (Larsen, 1997; Ortner, 2003). Ortner (2003) points out that other infectious agents, such as viruses, fungi, and multicelled parasites can also affect the bone marrow. The skeletal changes consist of bone destruction along with new bone formation (involucrum) and necrotic bone (sequestrum) (Aufderheide \& Rodriguez-Martin, 1998). Aufderheide \& Rodriguez-Martin (1998) argue that healed osteomyelitis leaves irregularities with sclerosis and cavities on the infected bone along with a general thickening and growth of the bone of about $1 \mathrm{~cm}$. Aufderheide \& Rodriguez-Martin (1998) discussed that acute osteomyelitis caused by infections due to compound fractures, injuries, or surgery, occurs most frequently in adults over 40 years of age.

The periosteal reaction is also considered as an indicator of infectious disease, which is characterized by the presence of "striae" on the surface of the long bone, as a reaction of the 
swelling of the periosteum or membrane which covers the osseous surface. When the swelling of the periosteum is generalized there is a sub-periosteal response that ends up as an increment in the diaphysis of the bone, being a deformed osseous segment observable (Steinbok, 1976: p. 115).

Dental pathology. Out of the diversity of the dental system, for the present work they were only taken as indicators to evaluate the conditions of oral health, abscesses and teeth wear or dental attrition, as they reflect in a general manner the conditions of health and alimentary habits of the population. Dental caries. It is a pathology that causes the demineralization and dissolution of dental tissues, caused by an acid-producing bacterium called Streptococcus Mutans, which is produced in the dental plaque on the teeth surface (Brothwell \& Sandison, 1967; Aufderheide \& Rodriguez-Martin, 1998; Goodman \& Martin, 2002). Caries are characterized by the formations of cavities, either on the occlusal surfaces or on any dental surface exposed to bacterial stagnation (Lagunas \& Hernández, 2000: p. 82). Abscesses. They might be caused by a fast wear that provokes a diminution of dentine to fill the pulp, or are also the result of progressive caries which generate a dental infection frequently originating these abscesses; they are macroscopically observed in the maxillary and in the jaw (Lewis et al., 1986; Herrera et al., 2000). Attrition or teeth wear: a pattern of behavior in relation to the sort of alimentation or an occupational activity as for the use of dentition can be observed (Lagunas \& Hernández, 2000: p. 46).

Bone is a dynamic material which can change its morphology, size and robustness in response to prolonged activity (Robb, 1998; Eshed et al., 2004; Weiss, 2007; Villotte et al., 2010a, 2010b). As a result, greater activity and mechanical stress causes the bone to become shapelier, with ridges and depressions caused by muscle action. Constant stress can cause enthesopathies (bony processes) or cortical bone defects at the site of muscle or ligament attachments when they lose the capacity to properly absorb the stress imposed (Hawkey \& Merbs, 1995: p. 329). Enthesopathies are frequently caused by constant microtrauma, but may also be the result of inflammatory disease, endocrine or degenerative diseases as well as severe sudden trauma (Resnick \& Niwayama, 1983).

Osteoarthritis is a common condition in all skeletal populations. Bone changes are most visible around the margins of vertebral body surfaces or either on or peripherial to the margins of the articular surfaces of appendicular joints. Ortner (2003) provides the three major components of skeletal involvement in osteoarthritis: 1) the collapse of articular cartilage that results in bone on bone contact and in abnormal abrasion of the subchondral bone; 2) reactive bone formation (sclerosis) in the subchondral compact bone (eburnation) and in the trabeculae underlying the affected subchondral compact bone and possibly associated with cyst formation; 3 ) new growth of cartilage and bone at the joint margins (osteophytes). These degenerative changes may result from the activities that produce mild chronic, single acute or repeated severe functional stress (Stein-Bock, 1976; Ortner \& Putshar, 1985). The frequency of degenerative arthritis is correlated with age (Goodman et al., 1984).

\section{Traumatic Lesions}

Trauma may be defined many ways but conventionally is understood to refer to an injury to living tissue that is caused by a force or mechanism extrinsic to the body. Observable in archaeological material are types of trauma that leave a mark on the skeleton. Ortner \& Putschar (1985) categorized trauma into eight categories: fractures, dislocation (luxation), deformation, scalping, mutilation, trephination, traumatic problems resulting from pregnancy, and sincipital T mutilation. Studies of trauma in archaeological material tell us about the prevalence of accidents and the degree of aggression in a society. They can also give us an insight into the medical knowledge and level of care in that society (Arcini, 1999). As the discipline of palaeopathology has developed, the objectives of traumatic injury analysis have shifted from a focus on the identification and description of the earliest and the most unusual pathological specimens to the interpretation of the cultural, social, or environmental causes of traumatic injury; their relationship to biological variables, such as sex and age, that may have cultural or social relevance; and their temporal and spatial variation. Thus, interpretations of the cause of trauma in antiquity range from interand intragroup conflict (e.g. Angel, 1974; Jurmain, 1991; Khudaverdyan, 2009, 2010a; Liston \& Baker, 1996; Stewart, 1974; Walker, 1989; and others) to environmentally or occupationally facilitated misadventure and accident (e.g. Angel, 1974; Burrell et al., 1986; Grauer \& Roberts, 1996; Kelley \& Angel, 1987; Khudaverdyan, 2009; Lovejoy \& Heiple, 1981; and others). Of these lesions, fractures and bone wounds by intentional instrument use (trephination) are mainly significant in archeological populations (Manchester, 1983).

Trepanation represents the first evidence of a surgical technique in humans done without modern equipment and yet there is evidence, from healing patterns on the skull, that many individuals survived this surgery. According to Aufderheide's \& Rodriguez-Martin's Encyclopedia of Human Paleopathology (1998: p. 33), there are four distinguishable methods of trepanation that include grooving, scraping, drilling, and cutting. Trephination is caused by the intentional use of a sharp instrument for the removal of part of the skull vault, generally without damaging the underlying meninges and brain. This dangereous operation was performed for a variety of reasons: to alleviate the intracranial pressure produced by compressed fractures of the skull vault, to clean the wounds caused by fractures, to treat headaches, epilepsy, or other forms of mental illness and so on (Ortner \& Putshar, 1985). The trephination may also have been symbolic or ritualistic in its type.

\section{Historical and Archaeological Background}

The Armenian Highland - a crossroads linking the worlds of East and West (Figure 1).

The Kingdom of Urartu flourished in the Caucasus and eastern Asia Minor between the 9th century BC and 585 BC in the Armenian Highland. The Urartians established their sovereignty over all of Taron and Vaspurakan. The main rival of Urartu was the Neo-Assyrian Empire. During the reign of Sarduri I (834-828 BC), Urartu had become a strong and organized state. Sarduri made Tushpa (Van) the capital of Urartu. His son, Ishpuinis, extended the borders of the state by conquering what would later be known as the Tigranocerta area and by reaching Urmia. Menuas (810-785 BC) extended the Urartian territory up north, by spreading towards the Araratian fields. Argishtis I of Urartu conquered Latakia from the Hittites, and reached Byblos, Phoenicia, and he built Erebuni (Yerevan). The Medes under Cyaxares invaded Assyria later on in 612 BC, and 


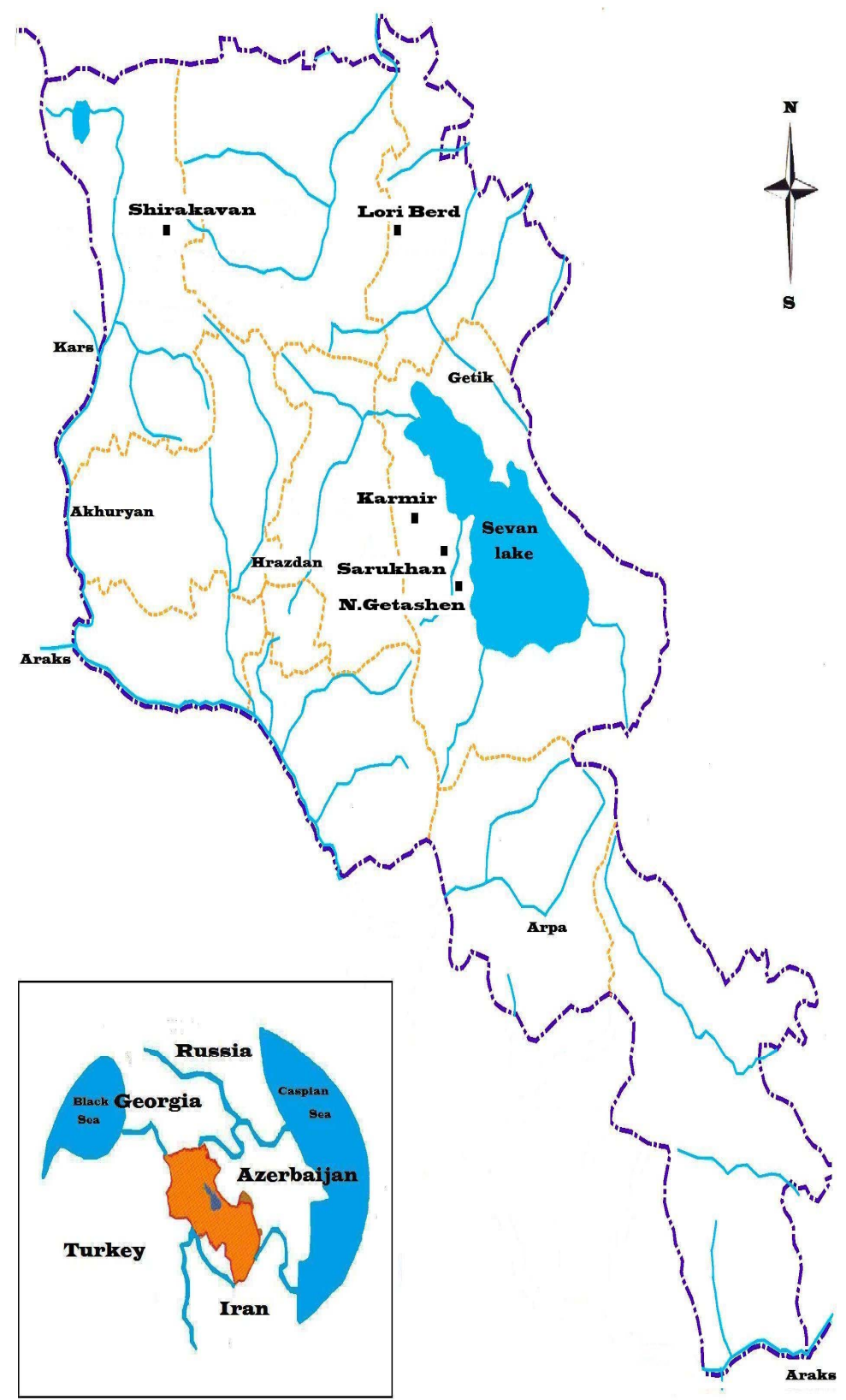

Figure 1.

Main sites discussed in text.

then took over the Urartian capital of Van towards $585 \mathrm{BC}$, effectively ending the sovereignty of Urartu. With VIII century $\mathrm{BC}$ in the Armenian Highland the interaction of different ethnocultural units-Iranian-speaking nomadic (Scythians, Sarmatians, Sauromatians, Saka) and local. Finds of tumuli in the Caucasus show the permanent presence of Scythians in these parts. The advancement of the Scythians, Sarmatians and Saka in the territory of Armenian highlands and Transcaucasia was accompanied by not only an interaction of various cultural elements, but also a mixture (Khudaverdyan, 2011a, 2012). According to archeologists, the Scythian presence in the Caucasus had been permanent (Vinogradov \& Dudarev, 1983; Petrenko, 1983; Il'inskaya \& Terenozhkin, 1983).

The aim of the paper is to assess the health of population of
IX-VI century BC from the Shirakavan cemetery. This cemetery are located in Shirak plateau, Armenia. No research has been done on the health status of Iron Age people from Shirak plateau before. This paper reports on the results of diseases associated with stress, trauma, as well as infectious and degenerative diseases etc.

\section{Materials and Methods}

The human remains that will be analyzed for this article unearthed by archaeologists Hamazasp Khachatryan, Larisa Eganyan and Levon Petrosyan. The results of the excavations at ancient Shirakavan showed that human activities began here since the 3 rd millennium BC and continued until the 7th-6th 
centuries BC. The excavated sample material sheds light on various sides of the life of ancient inhabitants of the region, testifying convincingly that a complex culture existed all over the Shirakavan was an important element of this system (Torosyan et al., 2002). Burials of leaders are rich, especially in the 9th-8th centuries BC: early 1st millennium seemed to be a time of the social and economic relations and high military potency. Excavations of some settlements confirm this supposition. Altogether, about 21 individuals were found from Shirakavan (excavations 2007-2011) (Table 1).

Some skeletons were lost, and all available remains were used. The major excavations at Sirakavan yielded material culture of the period known as Iron Age (9th century BC-6th century $\mathrm{BC})$. Males individuals predominated $(57.2 \%$ of the 21 individuals sexed): $19.1 \%$ of the young adults (20 - 39 years), and $38.1 \%$ of middle and older adults. $42.9 \%$ were female (23.9\% of adolescent and young adults and $19.1 \%$ of middle adults). The attention prevalence absence of skeletons of babies in burial grounds is noteworthy. The absence of babies' skeletons is probably connected with the tradition of burial existing among the juvenile population or some other ceremony.

Age-at-death and sex were assessed through the use of multiple indicators. Morphological features of the pelvis and cranium were used for the determination of sex (Phenice 1969; Buikstra \& Ubelaker, 1994). A combination of pubic symphysis (Gilbert \& McKern, 1973; Katz \& Suchey, 1986; Meindl et al., 1985), auricular surface changes (Lovejoy et al., 1985), degree of epiphyseal union (Buikstra \& Ubelaker, 1994), and cranial suture closure (Meindl et al., 1985) were used for adult age estimation.

Teeth and bones were examined for pathological lesions by means of simple macroscopic visual observation. Gross observations of abnormal changes appearing in ancient skeletons principally provides the basic information for paleopathological diagnosis (Goodman et al., 1984; Ortner, 2003). Non-specific signs of disease that were assessed include enamel hypoplasia, cribra orbitalia and subperiosteal bonegrowth/periostitis. The number of affected individuals and teeth for each disease were calculated as percentages of the total number of observed individuals or teeth in order to determine the prevalence of each disease. Cribra orbitalia was recorded as present or absent on individuals whose orbital roofs were present. All complete and fragmented crania were examined for porotic hyperostosis. Association between porotic hyperostosis and cribra orbitalia was recorded where present. Enamel hypoplasia was evaluated by means of the identification of lines of detention of enamel

Table 1.

Number of individuals from Shirakavan $(\mathrm{n}=21)$.

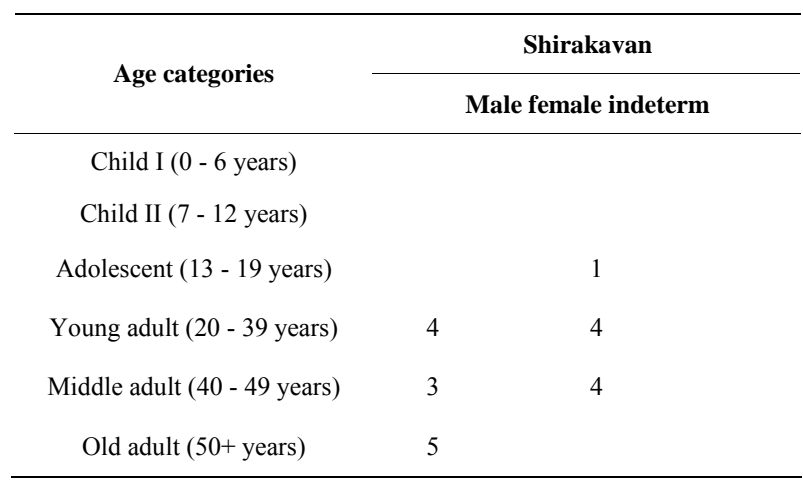

growth, a problem that is also associated with disturbances in the individuals' nutrition. Adults were examined for signs of arthritic and degenerative diseases. Scoring criteria. For this analysis I used the visual reference system devised by Hawkey (Hawkey \& Merbs, 1995). The scoring system consists of three main categories: robusticity markers, stress lesions, and ossifycation exostosis. Each category has four grades of increasing expression of musculoskeletal stress marker (MSM) where $0=$ absent and 3 = strong (Hawkey \& Merbs, 1995; Mariotti et al., 2004). Robusticity markers are expressed as rugged markings at the musculoskeletal attachment site and are the normal skeletal reaction to daily activities (Hawkey \& Merbs, 1995; Mariotti et al., 2007). The scores range from no rounding of the cortex to the formation of sharp crests of bone at the attachment site. Since muscle has a lower tensile strength than tendon, muscle-to-bone attachments require a larger area of attachment to prevent rupture when stressed (Hawkey \& Merbs, 1995: p. 329). At tendon attachment sites, such as the biceps brachii insertion site on the radial tuberosity, it is the area adjacent to the insertion site that shows the effects of muscular pull (Hawkey \& Merbs, 1995). A mesenchymal cell barrier, composed of layers of calcified and uncalcified layers of hyaline cartilage, between the tendon and bone prevents the resorption or formation of new bone at the attachment site (Hawkey \& Merbs, 1995: p. 328 ), thus the scoring criteria used must reflect the difference.

All skeletons were also assessed for specific diseases. Where possible, a differential diagnosis was made. The data previously obtained for Lori Berd (c. VI-V BC), Karmir (c. IX-VIII BC), N. Getashen III and Sarukhan (c. XI-IX/VIII BC) (Movsessian, 1990; Khudaverdyan, 2011b) were used for comparative analysis.

\section{Results and Discussion}

\section{Trauma and Trepanation}

One old-aged male was found to have undergone two surgical procedures. The defect (in diameter approximately $34 \mathrm{~mm}$ ) on skull is not round-it appears round in the upper part and then has straight sides more inferiorly. The hole was in the left panrietal bone (see Figure 2). This was a common piece of surgical kit carried by practitioners during this period. Differential diagnosis for this defect include weapon injury (depressed fracture with the section of bone removed surgically) or trepanation. The scalp had been ressected; several fine incision marks were observed around the line of the craniotomy cut, some parallel to each other, around the sides of the head. It is likely then that the scalp from the top of the head was removed by cutting across the front and along the sides, (roughly following the hairline in front but cutting through it posteriorly) and then lifting the scalp back, making subdermal incisions to the back of the head to further the reflection of the scalp to allow the craniotomy.

The cranium of this individual possesses multiple lesions that should allow determination of the underlying disease process. Differential diagnosis of lesions of the cranial vault includes treponematosis, depressed fractures, bacterial osteomyelitis, tuberculosis, benign and malignant primary tumors, metastases, hematological malignancy, and postmortem damage (Ortner \& Putschar, 1985). On the right side of the frontal bone the lesions corresponds with osteomyelitis. Pathological changes observed in the cranial vault include several focal cavitations that penetrate into the diploë but do not affect the inner table. There are 


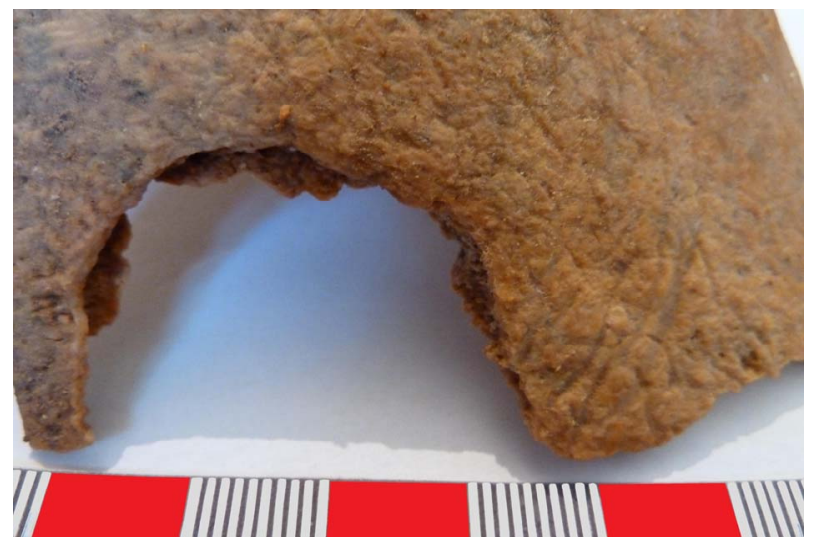

Figure 2.

Trepanation (burial 11, ภ 55 - 60 years).

also compact bone depressions with radial grooves that create a stellate pattern (Figure 3). The cranial lesions in this case are focused on the frontal bone. The anterior endocranium contains regions of hypervascularity and thickened diploë. Some postmortem erosion of the frontal bone is also present, with flaking and crumbling of the external cortex.

An ancient skull (1st c. BC-3rd c. AD) from Shirakavan (excavations in 1990) also showed evidence of trepanation (Khudaverdyan, 2011c: Figure 3). The individual was a juvenile (8 - 9 yr. old). Trepanation, achieved using a drilling technique, created a hole which was noted on the right parietal bone of the funnel-shaped type (diameter $=8 \mathrm{~mm}$ ). Since there was no evident biological reason to trepan this individual, and given the fact that this individual was quite young, it was possibly part of a ritual or religious ceremony. Perhaps the child died not from the trepanation process, but from complications of the surgery.

Several skulls showed evidence of traumatic injury. Trauma found in the skeletal populations from the Shirak plateau has often been put into the context of interpersonal conflict. Evidence of traumatic events in the Shirakavan group were in three individuals. The trauma were produced long before the individual's death (burial 4/2, of 25 - 30 years, Figure 4(a)), the margins are smoothed and the initial compressed bone region has been reduced and replaced by normal bone, because the fracture occurred several years before death. The trauma (burial 1, $\delta 20$ - 25 years, Figure 4(c)) shows a large angular blade wound, $7 \mathrm{~cm}$ long, broad and $2.5 \mathrm{~mm}$ deep, which occurs above the right parietal bone. This antemortem wound does not perforate the endocranium. This wound was produced by a blow from an anterior position; the blade-most likely. Perimortem typical defect found on the skull (Figure 4(b), burial 4, view on the outer table) the male 30 - 35 years. Singular punctured sharp force trauma on the parietal bone, most probably caused a hammerhead. The imprint of the wound could be recovered. Because of the form and the frequency of its appearance, the hammer was most probably the weapon that caused lesion. The only metal objects that show an approximately round profile are a special kind of lancet peak, and a hammerhead similar to those used today by masons and brick workers.

\section{Degenerative Disease and Musculoskeletal Stress Markers}

Degenerative joint disease directly affects the musculoskeletal

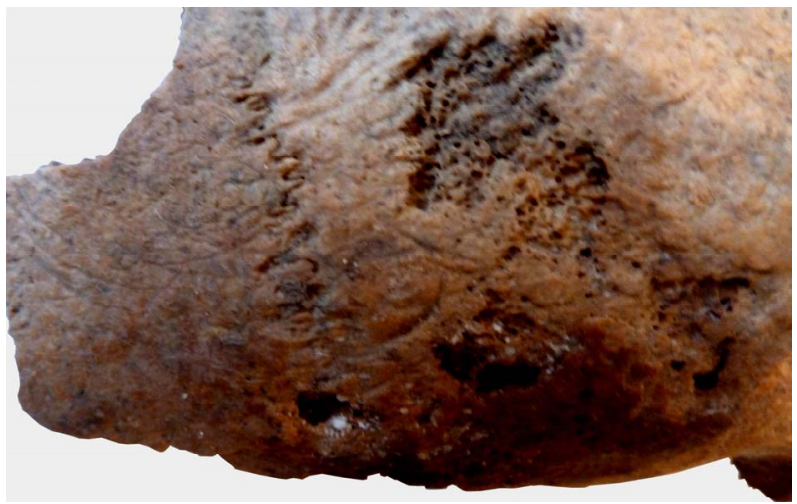

\section{Figure 3.}

Detailed view of ectocranial lesions: superficial cavitation perforating into the diploë. The lesion exhibits stellate grooves and a sclerotic margin.

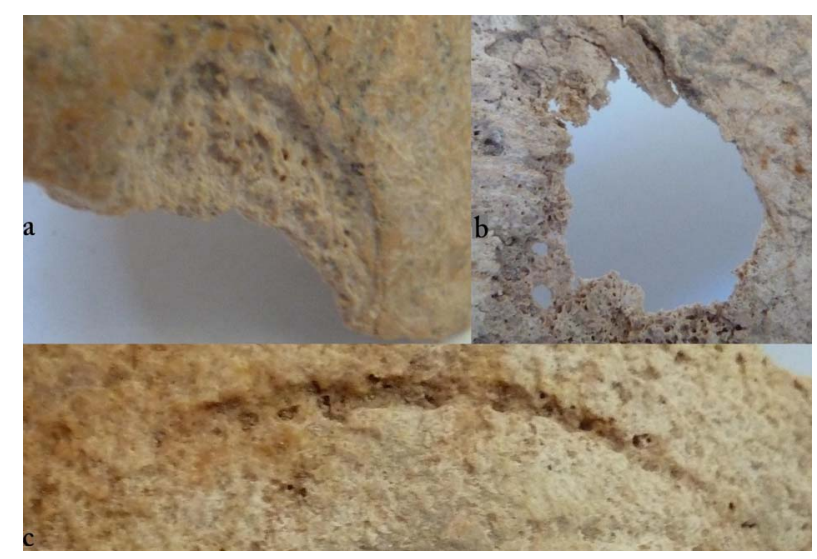

\section{Figure 4.}

Typical antemortem (a), (c) and perimortem (b) defects found on the crania. Burial $4 / 2$ healed blunt force trauma on the right parietal bone, produced several years before death (a, view on the outer table; scale bar $=19 \mathrm{~mm}$.); sharp force trauma on the right parietal bone most probably caused by a cut (c, burial 1); typical perimortem (b) defect found on the skull/burial 4, view on the outer table/; singular punctured sharp force trauma on the parietal bone, most probably caused a hammerhead.

system, which acts as a support and protection of the body, giving it a function of lever in a system of pulleys, where the muscles are inserted in the bones, hence producing the movement of the skeleton. According to the sort of movement, frequency and repetition, we can infer which the wear and/or joint condition may have been that produces, from light discomforts and pain to functional impotence. I rather focus on the fields of biomechanical origin; in this sense, when an unbalance in the forces applied to the joints appears and there is wear in the tissue to resist such efforts, mechanical articular deterioration arises. For the present study, the registration and analysis of this problem was sought in the shoulder-elbow, hip-knee, hand and feet joints, because of the high altitudes the group lived in, to evaluate this articular problem. The hip-knee problems, we observed that among women are four cases $(n=7)$ and in the group of men-six $(n=5)$; whereas in joint problems in hands and feet, we find five cases in women and six in men.

The activities performed by the individuals who inhabited in the Shirak plateau are represented in adult ages $(n=12)$. The 
presence of the aforementioned degenerative joint diseases suggests an intensive locomotive activity in the case of feet, across mountainous terrains. We also should consider the possibility that the transportation of heavy objects across the highlands.

Considerable muscle trauma was observed in skeleton (burial 6 , o 30 - 35 years), which may have caused discomfort. The enthesopathies observed in skeleton affected muscles aiding flexion and extension of the forearm, plantar flexion of the foot, extension and flexion of the leg at the knee joint and particularly all movements of the hip (Figure 5). All of the lower limb enthesopathies affected those muscles which are responsible for movements required for walking and it is possible that long distance marching (in high mountains) may have caused the necessary stress to produce muscular trauma.

The ossification of tissues in elbow joint is a result of strenuous overuse of the muscle, ligament or tendon in that area. The elbow joint pathology is significantly more severe as the ulnae have developed an extension of bone on the posterior surface of the proximal end (Figure 6). This area of the ulna, which is where the insertion for the biceps brachii is located, is attributed to "carrying heavy loads while the elbows are tightly flexed" (Larsen, 2000: p. 189). This action is also verified by the noted strenuous use of the supinator on the ulna which works with the biceps brachii for turning the palm anterior and lifting something with one's elbows partially flexed. Activities associated with stress on the biceps brachii include woodcutting, blacksmithing (Capasso et al., 1999).

As for the problems in shoulders, elbows and hands, these might be associated with the activities of milling products such as grains, transportation of water, washing of clothing of food that imply constant movement and effort which may favor joint wear and the presence of degenerative problems, linked to the conditions proper to age. On the other side, we observe sturdy insertions of the deltoid in the clavicles; this muscle takes part in the extension and abduction of the humerus raising it, producing backward rotation and toward the column of scapula and clavicle. Said physical activity might be linked to the fact of moving heavy objects on the head or back, an activity closely related to men, causing at the same time injuries to the spine because of the crushing of the vertebral body.

Problems in vertebral column were detected through the presence of osteophytosis and the collapse of the vertebral body; appearing in the cervical, dorsal and lumbar vertebrae almost with the same frequency. Injuries to vertebral column are caused by work overload, which the population suffered from the sub-adult stages to advanced ages; this explains the sort of labor that was possibly carried out in the environment where they lived (Table 2).

A greater presence is observed among masculine population; this explains men worked very hard in the production and to consolidate their dwellings; this is why we dare say that social conditions to survive were arduous for certain population sector. Nonetheless, we cannot state this for there is not enough archaeological information associated to the death so as to infer their social rank, according to the place they held in society. What we may infer is that biomechanical stress to work overloads, particularly the back, as for the articular problems of the vertebral column. In any case, we must bear in mind that said indicators appear in the bone only if the individual has usually repeated certain activities, or if within a certain period of their lives the individuals have carried them out with great intensity.

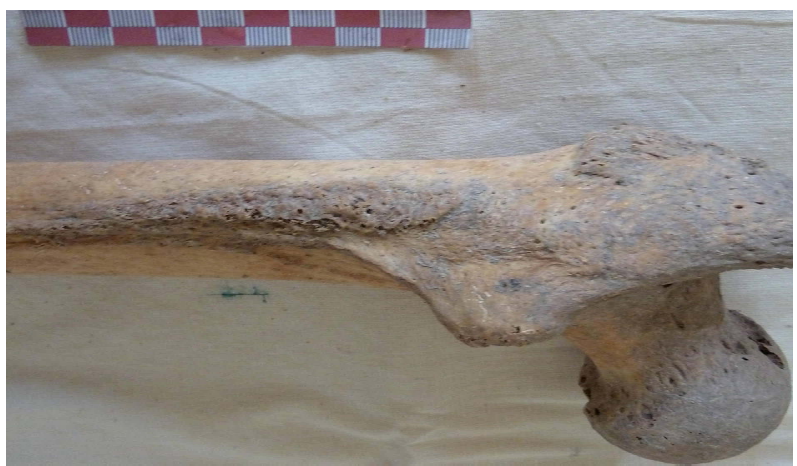

Figure 5.

Left femur of skeleton (burial 4, $\widehat{\jmath} 30-35$ years), enthesopathies for gluteus maximus.

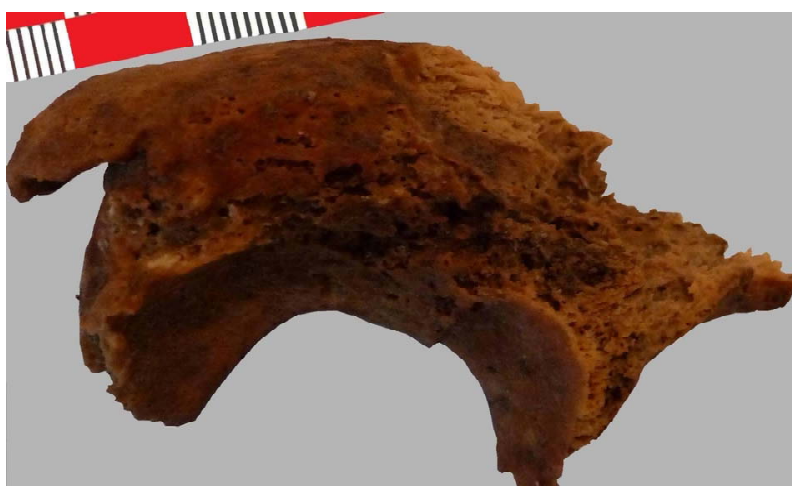

Figure 6.

Proximal end of the left ulna, showing arthritic lipping on articular facets and ossification of connective tissues (burial 11, $\widehat{\delta} 55-60$ years).

It is important to mention the age aspect, because if the individual died at a relatively early age, they might have not shown any character, or if they were too old their osseous tissue may have remodeled and lose the trace of any indicator. The same might occur if the activity significantly changes along their lives.

\section{Estimation of the General State of Health Based on Stress Markers}

In the materials of Shirakavan we find a high incidence of cribra orbitalia in $9(42.9 \%, 4$ of men, 5 women) of the 21 evaluable individuals. As for sponge or porotic hyperostosis, it appeared five times $(23.9 \%)$ : two men and three women. The women buried in the burials show a higher incidence of non-specific indicators of infection. The primary cause is usually iron-deficiency anaemia, which stimulates red blood cell production and bone marrow proliferation (Stuart-Macadam, 1992). In the burials in Shirakavan, mild cases of orbital roof involvement were found, suggesting iron deficiency related to infectious diseases and parasitism, which can also affect the occurrence of anaemia. Such causes as scurvy and direct infection cannot be excluded either (Larsen, 1997). The prevalence of cribra orbitalia is $28.6 \%$ from Sarykhan group and $8.8 \%$ from N. Getashen III (Movsessian, 1990). Two individuals ( $\mathrm{n}=$ 8) from Lori Berd showed evidence of cribra orbitalia (Khudaverdyan, 2011b).

Another unspecific marker of stress and deprivation, usually 


\section{A. YU. KHUDAVERDYAN}

Table 2 .

Problems in vertebral column in the total sample from Shirakavan $(n=12)$.

\begin{tabular}{cccccccc}
\hline & \multicolumn{2}{c}{ Cervical } & & Dorsal & \multicolumn{2}{c}{ Lumbar } \\
\cline { 2 - 7 } & Osteophytosis & Collapsed & Osteophytosis & Collapsed & Osteophytosis & Collapsed & Schmorl's \\
\hline Absence & 5 & 8 & 7 & 8 & 6 & 7 & 6 \\
Presence & 7 & 4 & 5 & 4 & 6 & 5 & 6 \\
\hline
\end{tabular}

associated with inflammation, is the presence of traces of periosteal reaction. Such periosteal inflammatory reactions, as well as more severe lesions, where bone marrow is affected, are most often caused by such microorganisms as Staphylococcus and Streptococcus, the tibia being the bone most often involved (Goodman \& Martin, 2002). A high incidence of this indicator in the skeletal remains makes it evident the presence of precarious or unhealthy conditions of the sanitary practices. The behavior of this periosteal reaction of infection in tibia was as follows: out of the 12 individuals who had the osseous element (tibia) to evaluate, 5 presented periosteal reaction. In relation to adults, in men there are two cases, one of about 21 years of age and another of around 26; whereas in women there are three cases, all of them located in the age range from 40 to 45 years of age. The results however low compared with other Armenia population (Lori Berd: 6 individuals, $\mathrm{n}=8$ ) are significant, as it is one of the indicators where more cases appear; which may indicate that infections manifested in this population in an endemic manner with severe hygienic problems because of polluted water.

Enamel hypoplasias represent a permanent chronological record of a stressful incident during the first 7 years of life (Goodman \& Rose, 1990). In individuals from Shirakavan there was no instance of line of hypoplasia. Six individuals from Sarykhan and three from Lori Berd showed evidence of enamel hypoplasias (Khudaverdyan, 2011b).

Dental caries is a multifactoral, multibacterial disease of dental tissue, characterised by local demineralisation of the inorganic portion of the tooth by acidproducing bacteria with subsequent destruction of the organic component by bacterial metabolic protease (Aufderheide \& Rodríguez-Martin, 1998). Caries is a progressive disease in that a continuation of the same environmental conditions that caused the lesion will inevitably lead to tooth destruction and loss. A relative not high frequency of dental caries was observed in Shirakavan (1/21) and in Lori Berd (1/8) samples. In individuals from Karmir, Akynk and Sarykhan there was no instance of dental caries (Khudaverdyan, 2011b).

If tooth destruction from any carious lesion penetrates the pulp cavity infection of the supporting tissues is almost inevitable. This leads to bone destruction around the base of the tooth root with sclerosis around the infection in chronic cases, followed by tissue necrosis, suppuration, and eventual periapical abscess formation within the alveolar bone. This may allow bacteria to enter the bloodstream (septicaemia) initiating abscesses in locations such as the long bones, vertebrae, heart valves or brain, often with fatal consequences (Aufderheide \& Rodríguez-Martin, 1998: p. 403). Alternatively the abscess may form a fistula or sinus, penetrating the alveolar cortical bone and allowing pus to drain into the oral cavity. Abscess was uncommon amongst the Shirakavan population, occurring in 1 young adult (burial 4/4,,+ 25 - 30 years). At Sarykhan, seven adults showed evidence of dental abscesses, which was higher than in the Akynk group, where only one individual was affected. Two out of four dentitions from Karmir showed evidence of dental abscesses.

Calculus was recorded on the teeth of $4 / 21$ individuals (burials $1 / 1,2,11,12)$ in the Shirakavan sample. It ranged in severity from slight $(n=1)$, through moderate $(n=3)$. The most severely affected teeth were the molars, premolars, canines, followed by the incisors. Calculus develops most commonly at loci close to the salivary glands, and is thus more common along the lingual margins of the lower anterior teeth and buccal margins of the maxillary molars. Although the presence of calculus is generally painless for the affected individual, the presence of substantial deposits can contribute to the development of periodontal disease and infections, and generally indicates a lack of oral hygiene. Four out of eight dentitions from Lori Berd showed evidence of dental calculus.

The individuals from Shirakavan also has fixed chipped teeth (antemortem damage to the crown of the tooth). Small pieces of enamel are missing on the buccal sides of the maxillary premolars, and the first maxillary molar (burials 6, 11).

Finally, attrition or dental wear was reflected in different age intervals, which range from the first 20 years of age to 55, also considering a slight to severe attrition (19.1\%); of the former 8 cases were found (38.1\%), six women among young and middle-aged adults, and two men between the same age intervals.

I found one case of marked dental modification in Shirakavan (Figure 7). Unusual wear of the right first upper premolar and development of a bone relief in area fastening a chewing muscle at the woman from necropolis Shirakavan (burial $6 / 2$,,+ 30 - 35 years) give the basis to assume wear of tooth as consequence of functional loading (i.e. use of a teeth as the working tool).

The grooves, $2.0 \mathrm{~mm}$ in width, give the appearance of being caused by repetitious sliding of a thin thread of sinew over the tooth. This have been associated with using the mouth to soften and hold fibers in the production of baskets, mats, fishing and fowling nets, and various types of cordage including rope and yarn (Larsen, 1985; Larsen et al., 1988; Scott \& Jolie, 2008; Waters-Rist et al., 2010). Activity-induced dental modification has been documented in past populations from all over the world, with archaeological and ethnographic data being used to infer possible causal activities (e.g. Merbs, 1983; Blakely \& Beck, 1984; Larsen, 1985; Larsen et al., 1988; Lukacs \& Pastor, 1988; Erdal, 2008; Scott \& Jolie, 2008; Waters-Rist et al., 2010). While it is not possible to determine the exact purpose(s) of processed fibers and cordage, it is reasonable to follow the example of other researchers who have used archaeological, environmental, and ethnographic data to suggest primary usages (e.g. Larsen, 1985; Scott \& Jolie, 2008; Waters-Rist et al., 2010). Such feature of teeth can be connected with weaving 


\section{A. YU. KHUDAVERDYAN}

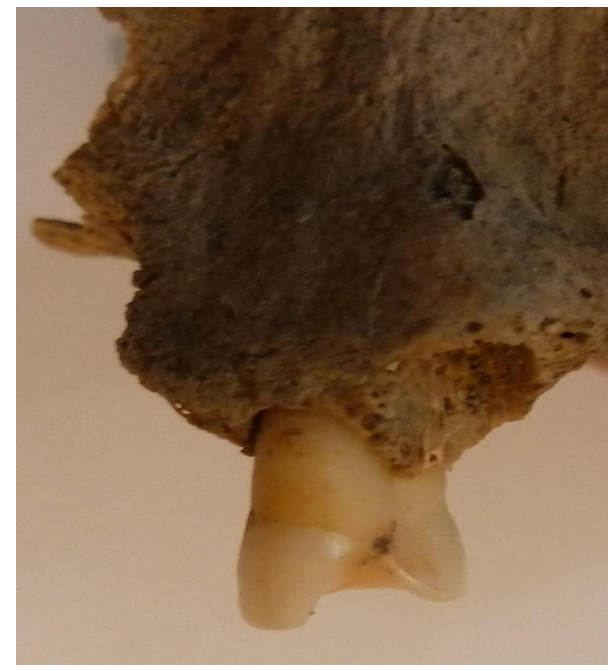

(a)

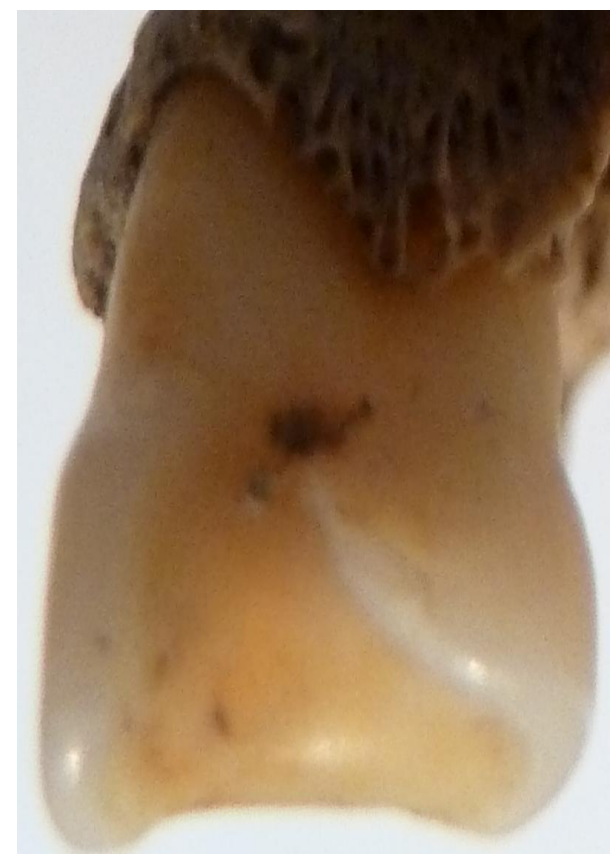

(b)

Figure 7.

Unusual wear of the right first premolar (burial 6/2, ㅇ, 30 - 35 years)

baskets. Archaeological data from Armenia provide evidence for the importance weaving and spinning, manufacturing of all kinds of cords, baskets in population of the Iron Age (Martirosyan, 1974; Torosyan, et al., 2002).

\section{Conclusion}

The Shirakavan burial assemblage presents a window onto the biological context of Iron Age Armenia. The burial ground thus presents a relatively small statistical sample, and it is clear from the demographic distribution that the assemblage most likely represents a culturally-biased artefact rather than a reflection of population mortality. The youngest individual died between 15 and 19 years of age, with the oldest well into ma- ture adulthood (50+ years). Males are over-represented within the adult assemblage. The bulk of the assemblage was comprised of middle-aged adult (20 to 49 years). The absence of infant remains is striking; segregated burial outside the social proscription of the burial ground is most likely-the outward continuation of a tradition which was firmly established in the Iron Age.

Shirak plateau was an ecologically favorable place for the reproduction of a society, as it offered a diversity of products for a balanced alimentation and well-suited to the biotic conditions of the place. Health issues in the individuals from Shirakavan provoked not by nutritional problems, but problems of infectious nature. This is observed inferring that the lifestyle of these people manifests a deficient personal hygiene, the contact with animals that carry fungi, viruses and bacteria, et cetera. Cribra orbitalia and porotic hyperostosis register a high percentage inside the sample, which allowed inferring this alteration has great repercussion on the population who suffered anemia, which may have been caused by several factors, among them we find: lack of iron or a deficiency of it caused by metabolic disorders, chronic parasitic diseases and the existence of other infectious diseases. Another aspect that was considered was that in the case of women the causes of anemia might have appeared because of the continuous pregnancies, starting in adolescence, birth itself, as they did not have the most favorable hygienic conditions and become infected, menstruation and a lengthy lactation.

The skeletal traumas of the inhabitants of the Shirak plateau are connected only with military conflicts. The investigation of injury morbidity and mortality facilitates the assessment of environmental, cultural and social influences on behaviour. By examining traumatic bone lesions in the archaeological record, we may reconstruct aspects of the physical and social environments of past populations. The data obtained indicates that the traumas are found exclusively among males. Although the sample size is small, the findings are consistent with the archaeological data. The one skull represents one of the oldest cases of trepanation in the Armenia.

As for the problems of degenerative nature, basically osteoarticular, they developed from adolescence to midlife or advanced ages, this is to say, they spanned along the inhabitants' life an caused numberless alterations at the level of musculoskeletal system, particularly in those bone segments where there was frequent and strenuous physical activity, such as the backbone joints result from biomechanical stress; such a problem affected men and women at different ages. The results of this study are those that suggest strenuous labor for at least some individuals, based on the presence of osteophytosis, osteoarthritis, enthesopathies, and Schmorl's nodes. The activities these inhabitants were been used to transport stone blocks, construction and manufacture of ceramic, among many others. Then, these actions leave a mark in the skeletons, product of a biomechanical activity. Then, these actions leave a mark in the skeletons, product of a biomechanical activity.

The data presented herein demonstrate that the analysis of activity-induced dental modification in archaeological samples can contribute to our behavioral reconstructions of past populations. This variation is perhaps not surprising, and is likely simply reinforcing the multiplicity of ways and activities in which people used their mouths and teeth. Indeed, a wide variety of extra-masticatory activities that in many cases caused dental modifications have been well-documented among an- 
cient peoples (1st c. BC-3rd c. AD) from Armenia (Beniamin, Vardbakh) (e.g. Khudavedyan, 2010b, 2011c). Activity-induced dental modification in woman from Shirakavan clearly show that teeth can record past habitual activity patterns, and provide an additional source of data in reconstructing past subsistence and material culture production systems.

We believe that the Shirakavan sample represents a unique and highly valuable collection of human skeletal remains from the Iron Age. Although the sample size was small, bioarchaeological data from the studied historical population of Shirakavan are useful in understanding the lifeways of the Armenian population in Iron Age.

\section{REFERENCES}

Angel, J. L. (1974). Patterns of fracture from Neolithic to modern times. Anthropologiai Közlemények, 18, 9-18

Arcini, K. (1999). Health and disease in early Lund. Osteo-pathologic studies of 3, 305 individuals buried in the first cemetery area of Lund 990-1536. Lund: Medical Faculty Lund University.

Aufderheide, A. C., \& Rodriguez-Martin, C. (1998). The Cambridge encyclopedia of human paleopathology. Cambridge: Cambridge University Press.

Blakely, R. L., \& Beck, L. (1984). Tooth-tool use versus dental mutilation: A case study from the prehistoric southeast. Midcontinental Journalof Archaeoogyl, 9, 269-284

Broth, W. D., \& Sandison, A. T. (1967). Disease in antiquity: A survey of the diseases, injuries and surgery of early populations. Springfield, IL: Charles C Thomas Publishers.

Buikstra, J. E., \& Ubelaker, D. H. (1994). Standards for data collection from human skeletal remains. Seminar at the field museum of natural history 44, Arkansas Archaeological Survey Research Series.

Buikstra, J. E., \& Cook, D. C. (1980). Paleopathology: An American account. Annual Review of Anthropology, 9, 433-470. doi:10.1146/annurev.an.09.100180.002245

Burrell, L. L., Mass, M. C., \& Van Gerven, D. P. (1986). Patterns of long-bone fracture in two Nubian cemeteries. Journal of Human Evolution, 1, 495-506. doi:10.1007/BF02437466

Capasso, L., Kennedy, K. A. R., \& Wilczak, C. A. (1999). Atlas of occupational markers on human remains. Journal of Paleopathology (Monographic publication 3), 3, 1-183.

Centurion-Lara, A., Castro, C. et al. (1998). The flanking region sequences of the $15-\mathrm{kDa}$ lipoprotein gene differentiate pathogenic treponemes. Journal of Infectious Diseases, 177, 1036-1040. doi: $10.1086 / 515247$

El-Najjar, M. Y., Ryan, D. J. et al. (1976). The etiology of porotic hyperostosis among the prehistoric and historic Anasazi Indians of Southwestern United States. American Journal of Physical Anthropology, 44, 477-488. doi:10.1002/ajpa.1330440311

Eshed, V., Gopher, A. et al. (2004). Musculoskeletal stress markers in Natufian hunter-gatherers and Neolithic farmers in the Levant: The upper limb. American Journal of Physical Anthropology, 123, 303315. doi:10.1002/ajpa.10312

Gilbert, B. M., \& Mckern, T. W. (1973). A method for aging the female os pubis. American Journal of Physical Anthropology, 38, 31-38. doi:10.1002/ajpa.1330380109

Grauer, A. L., \& Roberts, C. A. (1996). Paleoepidemiology, healing, and possible treatment of trauma in the Medieval cemetery population of St. Helen-on-the-Walls, York, England. American Journal of Physical Anthropology, 100, 531-544.

doi:10.1002/(SICI) 1096-8644(199608)100:4<531::AID-AJPA7>3.0. $\mathrm{CO} ; 2-\mathrm{T}$

Goodman, A. H., Martin, D. L. et al. (1984). Indications of stress from bones and teeth. In M. N. Cohen, \& G. J. Armelagos (Eds.), Paleopathology at the origins of agriculture (pp. 13-49). New York: Academic Press. doi:10.1002/ajpa.1330330506

Goodman, A. H., \& Martin, D. L. (2002). Reconstructing health profiles from skeletal remains. In R. H. Steckel, \& J. C. Rose (Eds.), The
Back-bone of history: Health and nutrition in the western hemisphere (p 11-60). Cambridge: Cambridge University Press.

Goodman, A. H., \& Rose, J. C. (1990). Assessment of systemic physiological perturbations from dental enamel hypoplasias and associated histological structures. Yearbook of Physical Anthropology, 33, 59-110. doi:10.1371/journal.pntd.0000148

Harper, K. N., Ocampo, P. S. et al. (2008). On the origin of the treponematoses: A phylogenetic approach. PLoS Neglected Tropical Diseases, 2, e148. doi:10.1371/journal.pntd.0000148

Hawkey, D. E., \& Merbs, C. F. (1995). Activity-induced musculoskeletal stress markers (MSM) and subsistence strategy changes among ancient Hudson Bay Eskimos. International Journal of Osteoarchaeology, 5, 324-338. doi:10.1002/oa.1390050403

Herrer, A. D., Roldan, S. et al. (2000). The periodontal abscess (I): Clinical and microbiological findings. Journal of Clinical Periodontology, 27, 387-394. doi:10.1034/j.1600-051x.2000.027006387.x

Il'inskaya, V. A., \& Terenozhkin, A. I. (1983). Scythia 7th-4th centuries $\mathrm{BC}$. Kiev.

Jurmain, R. D. (1991). Paleoepidemiology of trauma in a prehistoric central California population. In D. J. Ortner, \& A. C. Aufderhide (Eds.), Human paleopathology, current synthesis and future op- tions (pp. 241-248). Washington DC: Washington Smithsonian In- stitution Press.

Katz, D., \& Suchey, J. M. (1986). Age determination of the male os pubis. American Journal of Physical Anthropology, 69, 427-435. doi:10.1002/ajpa.1330690402

Kelley, J. O., \& Angel, J. L. (1987). Life stresses of slavery. American Journal of Physical Anthropology, 74, 199-211. doi:10.1002/ajpa.1330740208

Khudaverdyan, A. Y. (2009). Population of the Armenian highland during a Bronze Age. Ethnogenesis and ethnichistory. Yerevan: Van Arian.

Khudaverdyan A. (2010a). Pattern of disease in II millennium BC-I millennium $\mathrm{BC}$ burial from Lchashen, Armenia. Anthropologie (Brno), 3, 239-254.

Khudaverdyan, A. (2010b). Pattern of disease in three 1st century BC-3rd century AD burials from Beniamin, Vardbakh and the Black Fortress I, Shiraksky plateau (Armenia). Journal of Paleopathology, 22, 15-41.

Khudaverdyan, A. (2010c). Palaeopathology of human remains from Vardbakh and the black fortress I, Armenia. Bioarchaeology of the Near East, 4, 1-23. doi:10.2478/v10044-010-0004-1

Khudaverdyan, A. (2011a). Migrations in the Eurasian steppes in the light of paleoanthro-pological data. The Mankind Quarterly, 4, 387-463.

Khudaverdyan, A. (2011b). The anthropology of infectious diseases of Bronze Age and Early Iron Age from Armenia. Dental Anthropology, $2(2): 42-54$.

Khudaverdyan, A. (2011c). Trepanation and artificial cranial deformations in ancient Armenia. Anthropological Review, 74, 39-55.

Khudaverdyan, A. Y. (2012) A bioarchaeological analysis of the population of the Armenian highland and transcaucasus in the antiquity age. The Mankind Quarterly, 53, 3-35.

Lagunas, Z., \& Hernández, P. (2000). Manual de osteología, Mexico: Consejo nacional para la cultura y las Artes. Instituto nacional de antropología e historia. Escuela Nacional de Antropología e Historia: Secretaría de Educación Pública.

Larsen, C. S. (1985). Dental modification and tool use in the Western Great Basin. American Journal of Physical Anthropology, 67, 393-402. doi:10.1002/ajpa.1330670411

Erdal, Y. S. (2008). Occlusal grooves in anterior dentition among Kovuklukaya inhabitants (Sinop. Northern Anatolia, 10th century AD). International Journal of Osteoarchaeology, 18, 152-166. doi:10.1002/oa.925

Lallo, J., Armelagos, G. J., \& Mensforth, R. P. (1977). The role of diet, disease and physiology in the origin of porotic hyperostosis. Human Biology, 49, 471-483.

Larsen, C. (1997). Bioarchaeology. Interpreting behavior from the human skeleton. Cambridge: Cambridge University Press. doi: $10.1017 /$ CBO9780511802676 


\section{A. YU. KHUDAVERDYAN}

Larsen, C. S. (2000). Skeletons in our closet: Revealing our past through bioarchaeology. Princeton, NJ: Princeton University Press.

Larsen, C. S., Teaford, M. F., \& Sandford. M. K. (1988). Teeth as tools at Tutu: Extramasticatory behavior in prehistoric St. Thomas, US Virgin Islands. In J. R. Lukacs (Ed.), Human dental development, morphology, and pathology: A tribute to Albert A. Dahlberg (pp. 401-420). Eugene, OR: University of Oregon Anthropological Papers, No.54.

Lewis, M. A. O., Macfarlane, T. W., \& Mcgowan, D. A. (1986). Quantitative bacteriology of acute dento-alveolar abscesses. Journal of Medical Microbiology, 21, 101-104. doi:10.1099/00222615-21-2-101

Liston, M. A., \& Baker, B. J. (1996). Reconstructing the massacre at Fort William Henry, New York. International Journal of Osteoarchaeology, 6, 28-41.

doi:10.1002/(SICI)1099-1212(199601)6:1<28::AID-OA242>3.0.CO; $\underline{2-\mathrm{W}}$

Lovejoy, C. O., \& Heiple, K. G. (1981). The analysis of fractures in skeletal populations with an example from the Libben Site, Ottowa County Ohio. American Journal of Physical Anthropology, 55, 529-541. doi:10.1002/ajpa.1330550414

Lukacs, J. R., \& Pastor, R. F. (1988). Activity-induced patterns of dental abrasion in prehistoric Pakistan: Evidence from Mehrgarh and Harappa. American Journal of Physical Anthropology, 76, 377-398. doi:10.1002/ajpa.1330760310

Mariotti, V., Facchini, F., \& Belcastro, M. G. (2004). EnthesopathiesProposal of a standardized scoring method and applications. Collegium Antropologicum, 28, 145-159.

Mariotti, V., Facchini, F., \& Belcastro, M. G. (2007). The study of enthuses: Proposal of a standardised scoring method of twenty-three enthuses of the postcranial skeleton. Collegium Antropologicum, 31. 291-313.

Martirosyan, A. A. (1974). Argishtikhinili. Archaeological monuments from Armenia. Urartian monuments. Yerevan: Science.

Meindl, R. S., Lovejoy, C. O. et al. (1985). Accuracy and direction of error in the sexing of the skeleton: Implications for paleodemography. American Journal of Physical Anthropology, 68, 79-85. doi:10.1002/ajpa.1330680108

Merbs, C. F. (1983). Patterns of activity-induced pathology in a Canadian Inuit population. national museum of man mercury series, archaeological survey of Canada, Paper No. 119. Ottawa: National Museums of Canada.

Movsesyan, A. A. (1990). To the paleoanthropology of the Bronze Age in Armenia. Biological Journal of Armenia, 4, 277-283.

Ortner, D. J. (2003). Identification of pathological conditions in human skeletal remains (2nd ed.). London: London Academic Press.

Ortner, D. J., \& Putschar, W. G. J. (1985). Identification of pathological conditions in human skeletal remains. Washington, DC: Smithsonian Institution Press.

Petrenko, V. G. (1983). Scythian culture in the Northern Caucasus. Archaeological Collection of Articles of the State Hermitage, 23, Leningrad.

Phenice, T. W. (1969). A newly developed visual method of sexing the os pubis. American Journal of Physical Anthropology, 30, 297-302. doi:10.1002/ajpa.1330300214
Resnick, D., \& Niwayama, G. (1983). Entheses and enthesopathies. Radiology, 146, 1-9.

Robb, J. E. (1998). The interpretation of skeletal muscle sites: A statistical approach. International Journal of Osteoarchaeology, 8, 363377 .

doi:10.1002/(SICI)1099-1212(1998090)8:5<363::AID-OA438>3.0.C $\underline{\mathrm{O} ; 2-\mathrm{K}}$

Roberts, C., \& Manchester, K. (1995). The archaeology of disease. New York: Cornell University Press.

Scott, G. R., \& Jolie, R. B. (2008). Tooth-tool use and yarn production in Norse Greenland. Alaska Journal of Anthropology, 6, 253-264.

Steckel, R. H., \& Rose, J. C. (2002). The backbone of history: Health and nutrition in the Western Hemisphere. Cambridge: Cambridge University Press. doi:10.1017/CBO9780511549953

Steckel, R. H., Rose, J. C. et al. (2002). Skeletal health in the Western Hemisphere from $4000 \mathrm{BC}$ to the present. Evolutionary Anthropology, 11, 142-155. doi:10.1002/evan.10030

Steinbock, R. (1976). Paleopathological diagnosis and interpretation: Bone disease in ancient human populations. Springfield, IL: Charles Thomas Publisher.

Stewart, T. D. (1974). Nonunion of fractures in antiquity, with descriptions of five cases from the New World involving the forearm. The New York Academy of Sciences, 50, 876-891.

Stuart-Macadam, P. (1992). Porotic hyperostosis: A new perspective. American Journal of Physical Anthropology, 87, 39-47. doi:10.1002/ajpa.1330870105

Torosyan, R. M., Hnkikyan, O. S., \& Petrosyan, L. A. (2002). Ancient Shirakavan (the results of excavations 1977-1981). Archaeological excavations in Armenia. Yerevan: Gitutyun: Science.

Villotte, S., Castex, D. et al. (2010a). Enthesopathies as occupational stress markers: Evidence from the upper limb. American Journal of Physical Anthropology, 142, 224-234.

Villotte, S., Churchill, S. E. et al. (2010b). Subsistence activities and the sexual division of labor in the European Upper Paleolithic and Mesolithic: Evidence from upper limb enthesopathies. Journal of Human Evolution, 59, 35-43. doi:10.1016/j.jhevol.2010.02.001

Vinogradov, V. B., \& Dudarev, S. L. (1983). Chronology of some monuments and complexes at the beginning of the 1 st millennium BC from Karachaevo-Cherkesia and pyatigore. Problems of archaeology and ethnography of Karachaevo-Cherkesia). Cherkessk.

Walker, P. L. (1989). Cranial injuries as evidence of violence in prehistoric southern California. American Journal of Physical Anthropology, 80, 313-323. doi:10.1002/ajpa.1330800305

Waters-Rist, A., Bazaliiskii, V. I. et al. (2010). Activity-induced dental modification in holocene Siberian hunter-fisher-gatherers. American Journal of Physical Anthropology, 143, 266-278. doi:10.1002/ajpa. 21313

Weiss, E. (2007). Muscle markers revisited: Activity pattern reconstructed with controls in a central California amerind population. American Journal of Physical Anthropology, 133, 931-940. doi:10.1002/ajpa.20607

Wood, J. W., Milner, G. R. et al. (1992). The osteological paradox problems of inferring prehistoric health from skeletal samples. Current Anthropology, 33, 343-370. doi:10.1086/204084 